\title{
Governance of professional nursing practice in a hospital setting: a mixed methods study ${ }^{1}$
}

\author{
José Luís Guedes dos Santos ${ }^{2}$ \\ Alacoque Lorenzini Erdmann ${ }^{3}$
}

Objective: to elaborate an interpretative model for the governance of professional nursing practice in a hospital setting. Method: a mixed methods study with concurrent triangulation strategy, using data from a cross-sectional study with 106 nurses and a Grounded Theory study with 63 participants. The quantitative data were collected through the Brazilian Nursing Work Index - Revised and underwent descriptive statistical analysis. Qualitative data were obtained from interviews and analyzed through initial, selective and focused coding. Results: based on the results obtained with the Brazilian Nursing Work Index - Revised, it is possible to state that nurses perceived that they had autonomy, control over the environment, good relationships with physicians and organizational support for nursing governance. The governance of the professional nursing practice is based on the management of nursing care and services carried out by the nurses. To perform these tasks, nurses aim to get around the constraints of the organizational support and develop management knowledge and skills. Conclusion: it is important to reorganize the structures and processes of nursing governance, especially the support provided by the organization for the management practices of nurses.

Descriptors: Nursing, Supervisory; Hospital Administration; Management; Clinical Governance.

\footnotetext{
${ }^{1}$ Paper extracted from doctoral dissertation "Nursing professional governance practice in the hospital environment", presented to Universidade Federal de Santa Catarina, Florianópolis, SC, Brazil. Supported by Conselho Nacional de Desenvolvimento Científico e Tecnológico (CNPq), Brazil, process \# 474644/2012-0.

2 PhD, Adjunct Professor, Departamento de Enfermagem, Universidade Federal de Santa Catarina, Florianópolis, SC, Brazil.

${ }^{3}$ PhD, Full Professor, Departamento de Enfermagem, Universidade Federal de Santa Catarina , Florianópolis, SC, Brazil.
}

Corresponding Author:

José Luís Guedes dos Santos

Universidade Federal de Santa Catarina

Centro de Ciências da Saúde. Departamento de Enfermagem

Bairro: Trindade

CEP: 88040-970, Florianópolis, SC, Brasil

E-mail: jose.santos@ufsc.br
Copyright () 2015 Revista Latino-Americana de Enfermagem This is an Open Access article distributed under the terms of the Creative Commons Attribution Non-Commercial License (CC BY-NC).

This license lets others distribute, remix, tweak, and build upon your work non-commercially, and although their new works must also acknowledge you and be non-commercial, they don't have to license their derivative works on the same terms. 


\section{Introduction}

Management models are determined by organizational structures that assume characteristics of distribution of power, autonomy, communication and decision making. In the current context, the complexity of hospitals is associated with conflicts of interests, indicating the need to search for new theoretical references on the micro-politics of hospitals, as well as trying new management strategies ${ }^{(1)}$.

This need stems from the evolution of the construction of knowledge on organizational management. New social, economical, political and cultural circumstances have caused management to change rapidly toward the decentralization of the organizational structure, valorization of flexibility and more management autonomy ${ }^{(1)}$, characterizing the transition from a systems-control framework to a process-relational framework ${ }^{(2)}$.

In systems-control thinking, management corresponds to the classical approach to administration, based on operation control, hierarchies and centralizing the decision process ${ }^{(1)}$. Process-relational thinking, in its turn, aims at reorganizing management structures and models from the complexity perspective, which perceives uncertain, unpredictable and new aspects, as well as changes, to be continuous and permanent within organizations ${ }^{(2-4)}$.

In this changing scenario, the discussion of governance models has become more frequent in health and nursing management. The word "governance" refers to the process of collective action through which a society or organization defines decision-making mechanisms, as well as formal and informal operational structures within an institution(5). In health care, the term is used mainly in studies on best management practices to improve health care services and to allocate the available resources in the face of the increase of the population's health care demands(6).

In the context of nursing, professional governance corresponds to the processes and structures that provide autonomy, control and authority to nurses regarding the nursing practices within an organization ${ }^{(7)}$. The first governance model for nursing was designed in the 1980s, in the United States, and called "shared governance". Nowadays, its principles are widely disseminated internationally ${ }^{(8-9)}$. The model is based on the assumption that nurses, as the main frontline health workers, are more qualified to assess and decide which are the care needs of patients, based on parameters of clinical practice guidelines ${ }^{(7-8)}$.

In Brazil, the management work of nurses has been continuously and increasingly discussed, especially the contradictions and ambiguities related to the autonomy, leadership and decision making of nurses in health services $^{(1,10-11)}$. In spite of the relationship between these aspects and the concept of governance, integrative review shows no evidence of governance models being employed in nursing in Latin America, neither an application of the theoretical/conceptual framework of governance in nursing management ${ }^{(9)}$.

Brazilian nurses are believed to have developed their own strategies and mechanisms to implement governance in nursing practices, a dynamic process strongly related and associated with the organizational context and specificities of the professional nursing practice in the country. As a result, the following questions are proposed: what is the configuration of governance in nursing practice within a hospital setting? What meanings and experiences are correlated with this process?

The purpose of this study is to construct an interpretative model for governance in professional nursing practice within a hospital setting.

\section{Method}

Mixed methods research is conducted with a concurrent triangulation design, in which quantitative and qualitative data are simultaneously collected to compare and determine convergences, differences and combinations among them ${ }^{(12)}$. A quantitative study was carried out with cross-sectional outline, as well as a qualitative investigation guided by the constructivist principles of the Grounded Theory (GT) ${ }^{(13)}$.

The study location was a large-sized public university hospital with 268 beds, in Florianópolis, in the South region of Brazil. The institution is organized and structured into four divisions of nursing: Emergency and Ambulatory Care; Medical Care; Surgical Care and Women, Child and Adolescent Care.

For the quantitative study, the eligible population was comprised of 162 nurses. Inclusion criteria were performing nursing tasks and having worked for three months or longer on the location. Subjects that were absent owing to vacation or any type of leave of absence were excluded. Of the 132 nurses suitable for the research, 9 refused to participate and 17 did not return the instruments. As a result, 106 (80.3\%) confirmations were obtained, corresponding to the studied population.

Two instruments were applied: a sociodemographic characterization form and the Brazilian Nursing Work Index - Revised (B-NWI-R). The B-NWI-R was translated, adapted and validated for use in Brazil, 
and it measures certain characteristics of the work environment that favor professional nursing practice ${ }^{(14)}$. For data collection, we considered 15 items that compose four sub-scales: autonomy (five items), control over practice environment (seven items), nurse-physician relationship (three items) and organizational support (ten items derived from the first three sub-scales) ${ }^{(14-16)}$.

The B-NWI-R was used because there are no validated instruments specific for measuring governance in professional nursing practice in Brazil, and the choice was based on evidences from the literature which indicate that the B-NWI-R takes into account aspects related to the governance of professional nursing practice in a hospital setting(7-9).

A four-point Likert scale was used in the B-NWI-R. The participant is asked to answer if they agree or not with the affirmative "this factor is present in my daily work" and the following options are presented: totally agree (one point), partially agree (two points), partially disagree (three points) and totally disagree (four points), i.e., the lower the score, the higher the presence of positive attributes. Values below 2.5 represent an environment that favors professional practice, and averages above 2.5 indicate an environment that does not favor it ${ }^{(15-16)}$.

The collected quantitative data were tabulated in a Microsoft Excel ${ }^{\circledR}$ spreadsheet and analyzed in the program Statistical Package for the Social Sciences (SPSS), version 19.0, for Windows ${ }^{\circledR}$. To present the data, descriptive statistics was used to calculate measures of position and dispersion (mean, median, standard deviation, minimum and maximum values).

In the qualitative study, the theoretical sample of the GT was obtained through three Sample Groups (SG), with a total of 63 participants $(P): 1^{\text {st }}(\mathrm{SG}) 32$ hospital nurses ( $P 1$ to $P 32), 2^{\text {nd }}$ (SG) 13 nurse managers ( $P 33$ to P45) and $3^{\text {rd }}$ (SG) 18 health professionals (P46 to -63 ). In the $1^{\text {st }}$ and $2^{\text {nd }} \mathrm{SGs}$, representatives of the four nursing departments of the institution were included. In the $3^{\text {rd }}$ SG, nine technicians/nursing assistants, five physicians, two psychologists, one nutritionist and one speech therapist participated. Some of the nurses that participated in the quantitative phase also constituted the first sample group, but this was not a criterion for its composition.

From the data provided by clinical nurses, the sample groups were defined. Based on the interviews with the participants, we elaborated the hypothesis that governance in professional nursing practice is intrinsically correlated with the work of nurse managers and their socio-professional relationships with the nursing and health staffs. Thus, the two following sample groups were composed in order to search for data that supported or refuted this hypothesis.

The data were collected through intensive interviews ${ }^{(13)}$, carried out individually at the workplace or another location chosen by participants. They were recorded on an electronic audio device and lasted from 10 to $1 \mathrm{~h} 15$ minutes. The recordings were transcribed and


coding and organization. Data analysis was divided into an initial phase in which data segments was designated and a selective, focused phase, in which the most significant or frequent initial codes were sorted, integrated, synthetized and organized into categories and sub-categories ${ }^{(13)}$.

The study was approved by the reference Ethics Committee (CAAE: 09885612.1.0000.0121) and the participants signed an informed consent form. The statements of the interviewees were identified through codes constituted by the letter " $\mathrm{P}$ " (participant) and a number, according to the interviews carried out: P1 to P63.

The concurrent collection of quantitative and qualitative data was conducted from November 2012 until November 2013 in two phases, as Figure 1 shows. The qualitative and quantitative data were integrated to determine convergences, differences and combinations.

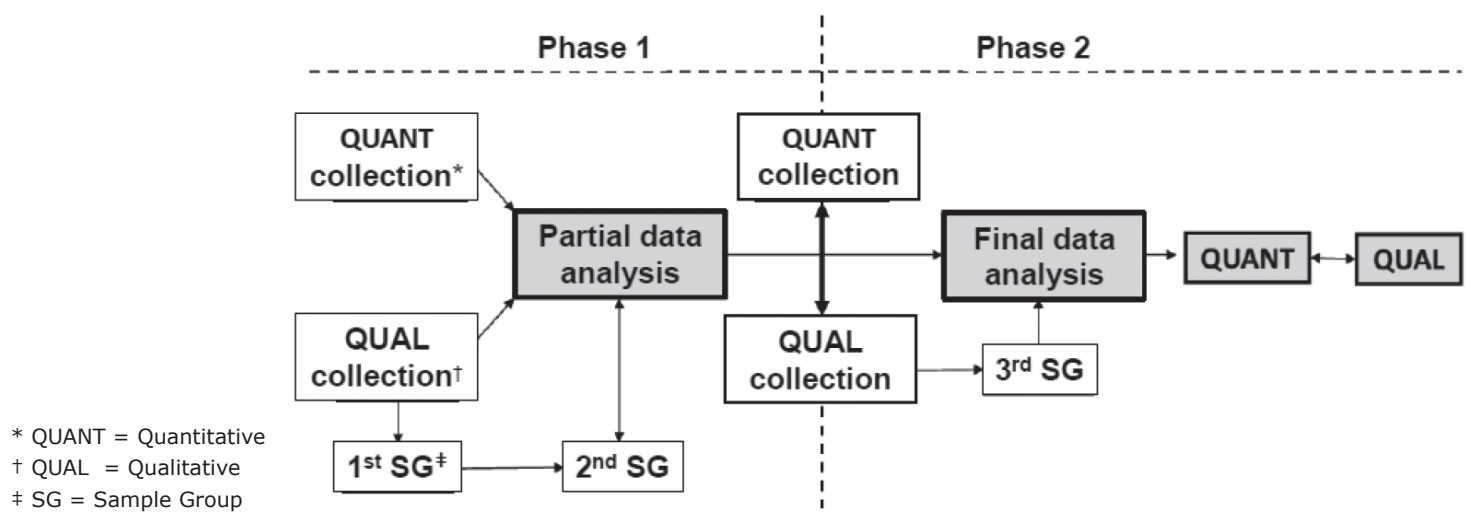

Figure 1 - Diagram representing the study design. Florianópolis, SC, Brazil, 2012-2013 


\section{Results}

In the analysis of the socio-demographic profile of the participants in the quantitative phase, we verified that their age ranged from 23 to 61 years, with a median of 48 years. The highest frequency belonged to age group 41-50 years. Of the 106 nurses, 53 (50\%) were married and $98(92.5 \%)$ were female.

The average of years of professional nursing experience was 13 years and six months ( $\min =6.96$ years; $\max =35$ years e Standard-Deviation $=\mathrm{SD} \pm 9.46$ ) and the average time working at the institution was 12 years ( $\min =6.96$ months; $\max =33.42$ and $S D \pm 9.69$ ). On average, they had 19.51 patients under their responsibility $(\min =4 ; \max =70$ and $S D \pm 13.06)$. They worked about 31.41 hours a week $(\min =30 ; \max =74$ and $\mathrm{SD} \pm 11.8)$ and $89(84 \%)$ did not have any other employment relationship.

The data obtained with the NWI-R are presented in Table 1.

Table 1 - Mean, standard deviation, median and variation of the sub-scales of the B-NWI-R* $(n=106)$. Florianópolis, SC, Brazil, 2012-2013

\begin{tabular}{|c|c|c|c|c|c|}
\hline & Mean & Standard deviation & Median & Minimum & Maximum \\
\hline Autonomy & 2.07 & 0.50 & 2.00 & 1.00 & 3.40 \\
\hline Control over practice environment & 2.48 & 0.54 & 2.42 & 1.14 & 3.86 \\
\hline Nurse-physician relationship & 2.14 & 0.54 & 2.00 & 1.00 & 3.67 \\
\hline Organizational support & 2.20 & 0.41 & 2.20 & 1.00 & 3.00 \\
\hline Total B-NWI-R* & 2.21 & 0.39 & 2.20 & 1.30 & 3.11 \\
\hline
\end{tabular}

*Brazilian Nursing Work Index - Revised

According to the results obtained with the B-NWI-R, the environment favored professional nursing practice. It is possible to affirm that nurses perceive themselves to have autonomy, control over the environment, good relationships with physicians and organizational support for the governance of nursing practice.
In the qualitative study, starting from the analysis of the GT data, the following phenomenon was obtained: implementing governance in the nursing practice within a university hospital, which is divided into four categories and their respective sub-categories, as Figure 2 shows.

\begin{tabular}{|l|l|}
\hline \multicolumn{1}{|c|}{ Categories } & \\
\hline $\begin{array}{l}\text { Getting around the } \\
\text { ambiguities of the } \\
\text { organizational support }\end{array}$ & $\begin{array}{l}\text { - Highlighting the work conditions of the institution } \\
\text { - Highlighting the importance of the support and assistance of the Nursing Directorate } \\
\text { - Facing people management difficulties in public services } \\
\text { - Confronting the bureaucracy and slowness of support services }\end{array}$ \\
\hline Managing nursing services & $\begin{array}{l}\text { - Assuming the managing job due to influence of coworkers and/or superiors } \\
\text { - Considering the managing position an opportunity for new learning } \\
\text { - Coordinating communication between clinical nurses and the Nursing Directorate } \\
\text { - Noticing that the onus is larger than the bonus }\end{array}$ \\
\hline Managing nursing care & $\begin{array}{l}\text { - Establishing and maintaining control over the hospital care environment } \\
\text { - Occupying a central position in the organization and in care services }\end{array}$ \\
\hline $\begin{array}{l}\text { Developing managing } \\
\text { knowledge and skills }\end{array}$ & $\begin{array}{l}\text { - Learning to manage throughout the professional career } \\
\text { - Choosing to follow good professional examples } \\
\text { - Highlighting the need of a nursing management training }\end{array}$ \\
\hline
\end{tabular}

Figure 2 - Table of categories and their respective sub-categories. Florianópolis, SC, Brazil, 2012-2013

Organizational support corresponds to the assistance provided by the institution for nursing governance. In the category "getting around the ambiguities of the organizational support", participants singled out positive and negative aspects of the governance of nursing practice, which justifies the mean obtained for the "control over practice environment" sub-scale from the B-NWI-R.

Work conditions, the size of the staff and the availability of material resources were considered adequate for providing nursing care. Moreover, the hospital has a Nursing Directorate with the same 
importance of its other managing bodies, and a nurse chosen by the nursing professionals holds the position of nurse manager. Organizational support difficulties are related to people management and bureaucratic constraints of the support systems.

The hospital provides a great structure, [...] we can create the schedule the way we find more appropriate, and we have more technicians and nurses at our disposal than other hospitals (P8). We can choose our own director, which is important because we do not have a superior imposed or indicated by a general director (P34). [...] people look at a mini-fridge, for instance, and they think that our superiors do not do anything, but it's actually the bureaucratic channels that get in the way [...] (P6) [...] since there is job security for civil servants, many people think that they do not have to show skills or commitment [...] (P11).

The category "managing nursing services" refers to the process of managing nursing in the institution. In addition to the nursing director, nursing management is also carried out by nurses that work as head of the division or head of nursing services. Four divisions of nursing are organized according to the main types of care provided by the institution: emergency and ambulatory care; medical care; surgical care and mother and child care. The divisions encompass 17 care units.

The heads of nursing services are responsible for managing a hospital unit and coordinating communication among clinical nurses and the Nursing Directorate. A nurse who works as head of a division coordinates the management of a group of similar units. To assist in nursing management, the Nursing Directorate has a Nursing Education and Research Center (CEPEN) and a Permanent Commission of Healthcare Products (CPMA) as advisory bodies in charge of managing the educational work of nursing and coordinating the process of planning, organizing and controlling healthcare products, respectively.

[...] the head of the unit acts as go-between with the nursing directorate (P43). The head of the division links the units $[\ldots]$, so when the head of the unit has a problem, he reports it to the head of the division (P5). [...] we receive plenty of support, especially from the CEPEN and the CPMA (P35).

This organizational structure increases the autonomy of nurses, in accordance with the quantitative results, which showed a favorable mean for the autonomy sub-scale.

The positions of head of the division and of nursing services are also elective, as well as the nursing director position. During data collection, the hospital was having difficulties in preparing new leaders for the managing positions. Many nurses, especially those that had been working in the institution for a longer time, reported having no interest on the positions due to the stress caused by managing tasks and to insufficient compensation.

[...] it is very demanding, very stressful, when you put yourself in charge of managing a sector (P13). The compensation is derisory; it is not enough for all the responsibilities (P33).

As a result, nurses who had worked in the institution for less time were taking most of these positions, influenced by coworkers and/or superiors, and because they were seeking new learning and professional challenges. In this sense, they were not always ready to fill the managing position.

Nobody wanted the position of head [...]. We talked and agreed on who should run (P5). Nobody wanted to run. Then my boss said: "go ahead, you have a suitable profile" (P39). [...] I felt like seeking new experiences and knowing other things, because in nursing care the person ends up in a routine $[\ldots]$ (P43). The people taking over management are not prepared. So it depends a lot on leadership skills and interpersonal relationships, knowledge, a strong position in the face of the multidisciplinary and medical staff (P38).

As a result, the category "developing management knowledge and skills" showed that learning management practices in the institution has occurred mainly throughout the professional career and from taking a nurse perceived as a good example as a model. Hence, the nurses suggested that a training and/or course focused on management and nursing leadership should be conducted.

I started working here when I was 26, very insecure. Life and the hospital itself ended up teaching me... [...]. Today I have an idea of what I can and should do, and of what is not up to me. Before I used to think that I needed to solve the entire world (P34). We take the people we look up to as models (P20). [...] I suggested training for the heads because we fill the position when nobody else wants it. It happens in $90 \%$ of the situations (P44).

Another important aspect of nursing governance is managing care, the main responsibility of clinical nurses, as singled out by the category "Managing nursing care". Nurses occupy a central position in the context of the organization and in providing care, serving as models for the health and nursing staffs. With that purpose, they aim at achieving a good overall perspective of the hospital care environment and at keeping up to date with the information of hospitalized patients, in order to contribute for their quality of care.

[...] we get a good overall perspective, the control of everything that is happening (P19). I always want to know what is going on [...], at times I am not around, but I am "on" to the 
situation (P29). The nurse is the one who answers my questions, helps my tasks and procedures [...] they are crucial for the unit (P60). Nurses have a good overall perspective of the unit, of how patients are doing, if exams need to be scheduled, if ambulances need to be scheduled, if this or that need to be done, if products need to be picked up [...] (P55).
The work of the nurse in care management explains the positive mean of the sub-scale "nursephysician relationship" of the B-NWI-R. Figure 3 shows the correlation among the sub-scales of the B-NWI-R, the presented subcategories and the studied phenomenon.

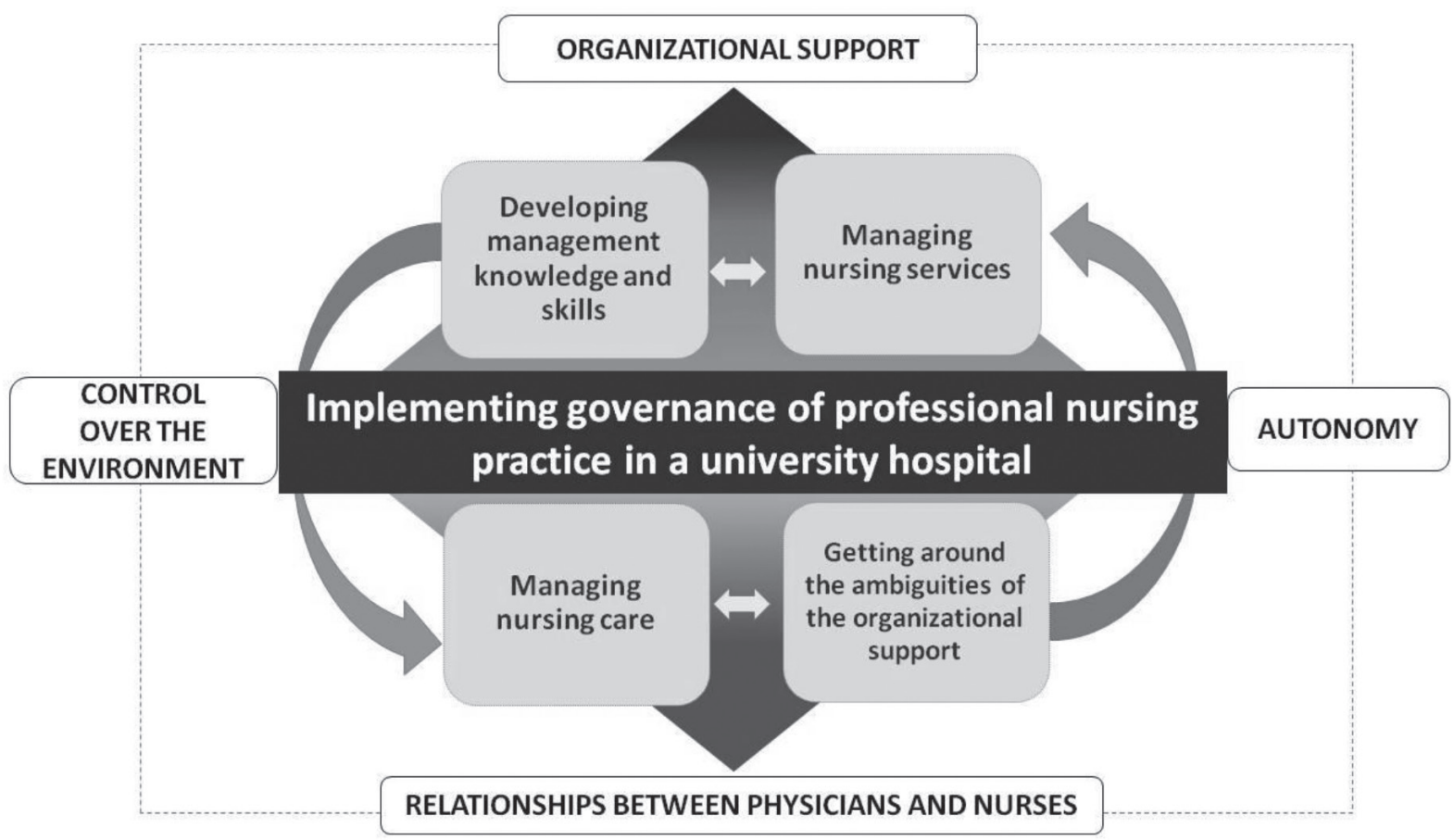

Figure 3 - Diagram representing the correlation among the sub-scales of the B-NWI-R, the categories and the phenomenon. Florianópolis, SC, Brazil, 2012-2013

\section{Discussion}

In the quantitative study, the average total score of the B-NWI-R is similar to the results of previous studies carried out in Brazil with the same instrument(15-16). However, the result obtained is below the means found in studies conducted in hospitals that adopt management models with shared governance principles ${ }^{(17-18)}$.

The qualitative results show that governance in nursing is based on managing nursing care and services. To perform these tasks, nurses seek to get around organizational support constraints and develop management knowledge and skills.

The term "nursing care management" reflects the complementarity between the managing and care aspects of the work of nurses. In nursing literature in Brazil, it has been used frequently to characterize the activities of nurses in planning care measures, predicting and providing resources for hospital care, coordinating interactions among workers of the health care staff and seeking better care practices ${ }^{(19)}$.

The tasks of nurses in nursing care management can be compared to the position of the Clinical Nurse Leader ( $\mathrm{CNL}$ ) in the United States, which is a nurse that implements measures to minimize communication and information gaps between the patient, the family and the health/nursing staff, aiming at improving quality of care and reliability of patient care results. Among their tasks, we single out speaking in favor of the patient, coordinating and planning nursing and health interventions and/or care and supervising and guiding new nurses ${ }^{(20-21)}$.

In the statements, the commitment of nurses to establish and maintain control over the hospital care environment in order to manage patient care stood out. The control nurses seek is related mainly to the systems-control framework, which does not consider the self-organizing potential of people and organizations. 
In this perspective, the manager is in charge of paying attention to the relationship networks that compose the organizational set as a whole and of developing skills to improve them, instead of focusing their attention on local and individual parts ${ }^{(2)}$.

The fact that nurses value control of the care environment may be related to their multipurpose and coordinating work. Nurses are responsible for coordinating and mediating the demands of the organization, the nursing staff and the patients. As a result, losing control would signify not fulfilling these responsibilities and therefore a sign of incompetence. However, it is necessary to consider that disorder and uncertainties stimulate creativity, innovation and evolution, which may lead to positive changes in nursing practice. Additionally, a dynamic and promising selforganization may gain strength from the individual characteristics of people due to their constant interaction, thus being influenced by the social whole ${ }^{(3-4)}$.

Regarding the position of head of nursing services, we observed that the institution found it difficult to prepare leaders willing to fill the position. The decision of nurses to run for the position stems mainly from the pressure of co-workers and/or superiors. Similar results are described in a Swedish research, according to which few nurses consciously choose to become leaders and to qualify for that ${ }^{(22)}$. Likewise, a study carried out in the United States singled out the lack of interest of new nurses in leadership positions and the difficulty of health organizations in recruiting qualified professionals for them(23).

The following reasons discourage interest in a managing position: the stress caused by its responsibilities, the difficulties in managing people and the slowness of support services. As a result, it is possible to carry out an analysis about motivation in the workplace. Traditionally, organizations adopt a rational system of rules and procedures that ensure tasks are fulfilled to guarantee that goals and objectives are met, without considering that the feelings of workers are relevant to the rational pursuit of material interests in the corporate context ${ }^{(2)}$. In this way, it is important to examine how the work environment contributes to the motivation of the employees, allowing them to express their potentials so they can feel like an essential part of the organization and aim at providing a better service.

To develop managing competences and skills, nurses highlighted the need to provide trainings focused on nursing management, which may be a relevant strategy since management learning in the institution occurs mostly empirically. Brazilian and international literatures frequently discuss the importance of developing, implementing and evaluating new strategies and models for the succession and creation of leaderships in nursing(10-11,23-25).

A study reports, for instance, the development of a succession planning model for nursing managers in North American hospitals. The model is composed of six steps: strategic planning, selection of participants, curricular development, implementation, evaluation and allocation of professionals. The activities involve face-to-face and online courses on leadership and management, elaboration of professional portfolios and tutoring strategies, and coaching. Hence, the program has effectively increased the self-assessment of nurses regarding leadership and competence, in addition to stimulating personal and professional development(25).

Similarly, a study conducted by Swiss researchers showed the positive results of a Clinical Leadership Programme, which lasted 147 hours over a 12 month period, with lectures, coaching and workshops ${ }^{(24)}$. These initiatives are important since the lack of guidance and formal education in nursing management has been associated with stress in management tasks, negative results related to quality of care and a high turnover of professionals ${ }^{(23,25)}$.

Professional education programs for nursing management need to focus on learning to comprehend the complexity of relational processes, using all human skills. An education based on rationality does not enable "learning to live with others and to be", which involves the ethical, moral and relational aspects ${ }^{(4-5)}$ inherent to management practices.

\section{Conclusion}

The governance of professional nursing practice is based on managing patient care and nursing services within a hospital setting. To succeed in these tasks, nurses aim at getting around difficulties related to managing people in public services and slowness in support services. Management knowledge to implement governance comes from professional experience and choosing good professional examples as models.

The results presented in this article can contribute to reorganize the structures and processes of governance in nursing practice, especially regarding the support provided by the organization for the management 
practices of nurses. We also highlight the importance of investing in training and enhancement programs focused on management knowledge and skills for the nurses. Coordinating and connecting management and nursing knowledge from a perspective of organizational complexity may improve the governance of professional nursing practice.

The limitations of the study are related to the quantitative sample, which was small $(n=106)$. In addition, data collection was conducted in only one hospital. Studies with a higher number of participants and more hospital settings will provide more representative results for the studied phenomenon. We aimed at improving the consistency of the results and meeting the proposed goal by coordinating quantitative data with the findings of a GT with different actors of the hospital setting.

\section{Acknowledgements}

To Dr. Mary K. Anthony from Kent State University's College of Nursing for the suggestions that enabled the theoretical improvement of the doctoral dissertation from which this article was derived.

\section{References}

1. Hayashida KY, Bernardes A, Maziero VG, Gabriel CS. A tomada de decisão da equipe de enfermagem após revitalização do modelo compartilhado de gestão. Texto Contexto Enferm. 2014;23(2):286-93.

2. Watson TJ. Organização e trabalho em transição: da lógica "sistêmico-controladora" à lógica "processualrelacional". Rev Adm Empres. 2005;45(1):14-23.

3. Serva M, Dias T, Alperstedt GD. Paradigma da complexidade e teoria das organizações: uma reflexão epistemológica. Rev Adm Empres. 2010;50(3):276-87. 4. Caveião $C$, Hey $A P$, Montezeli JH. Administração em enfermagem: um olhar na perspectiva do pensamento. Rev Enferm UFSM 2013;3(1):79-85.

5. Lange $P$, Driessen PPJ, Sauer A, Bornemann B, Burger P. Governing towards sustainability conceptualizing modes of governance. J Environ Pol Plan. 2013;15(3):403-25.

6. Dieleman M, Shaw DMP, Zwanikken P. Improving the implementation of health workforce policies through governance: a review of case studies. Hum Resour Health 2011;9:10.

7. Barden AM, Griffin MTQ, Donahue M, Fitzpatrick JJ. Shared governance and empowerment in registered nurses working in a Hospital Setting. Nurs Adm Q 2011;35(3):212-8.

8. Hess RG, Swihart D. Shared Governance: what it can mean for nurses. Nursing Spectrum 2013;25(1):38-43.

9. Santos JLG, Andrade SR, Mello ALSF, Lima SBS, Pestana AL. Governança em enfermagem: revisão integrativa. Rev Esc Enferm USP. 2013;47(6):1417-25.

10. Dall'Agnol CM, Moura GMSS, Magalhães AMM, Falk MLR, Riboldi CO, Oliveira AP. Motivations, contradictions and ambiguities in the leadership of nurses in management positions in a university hospital. Rev. Latino-Am. Enfermagem. 2013;21(5):1172-8.

11. Amestoy SC, Backes VMS, Thofehrn MB, Martini JG, Meirelles BHS, Trindade LL. Nurses' perception of the teaching-learning process of leadership. Texto Contexto Enferm. 2013;22(2):468-75.

12. Fetters MD, Curry LA, Creswell JW. Achieving integration in mixed methods designs - principles and practices. Health Serv Res 2013;48(6 pt2):2134-56.

13. Higginbottom G, Lauridsen EI. The roots and development of constructivist grounded theory. Nurse Res. 2014;21(5):8-13.

14. Gasparino RC, Guirardello EB. Tradução e adaptação para a cultura brasileira do "Nursing Work index Revised". Acta Paul Enferm. 2009;22(3):281-7.

15. Gasparino RC, Guirardello EB, Aiken LH. Validation of the Brazilian version of the Nursing Work Index-Revised (B-NWI-R). J Clin Nurs 2011;20(23-24):3494-501.

16. Panunto $M R$, Guirardello EB. Professional nursing practice: environment and emotional exhaustion among intensive care nurses. Rev. Latino-Am. Enfermagem. 2013;21(3):765-72.

17. Dewaelheyns N, Eeckloo K, Van Herck G, Van Hulle $C$, Vleugels A. Do non-profit nursing homes separate governance roles? The impact of size and ownership characteristics. Health Policy. 2009;90(2-3):188-95.

18. Clavelle JT, O'grady TP, Drenkard K. Structural empowerment and the nursing practice environment in Magnet $\AA$ organizations. J Nurs Adm. 2013;43(11):566-73.

19. Christovam BP, Porto IS, Oliveira DC. Nursing care management in hospital settings: the building of a construct. Rev Esc Enferm USP. 2012;46(3):734-41.

20. Tornabeni J, Miller JF. The power of partnership to shape the future of nursing: the evolution of the clinical nurse leader. J Nurs Manag. 2008;16(5):608-13.

21. Tomey AM. Nursing leadership and management effects work environments. J Nurs Manag. 2009;17(1):15-25. 
22. Bondas T. Paths to nursing leadership. J Nurs Manag 2006;14(5):332-39.

23. Collins SK, Collin KS. Changing workforce demographics necessitates succession planning in health care. Health Care Manage. 2007;26(4):318-25. 24. Martins JS, Mccormack B, Fitzsimons D, Spirig R. Evaluation of a clinical leadership programme for nurse leaders. J Nurs Manage. 2012;20(1):72-80.

25. Titzer JL, Shirey MR, Hauck S. A nurse manager succession planning model with associated empirical outcomes. J Nurs Adm. 2014;44(1):37-46. 